\title{
Lung and kidney: a dangerous liaison? A population-based cohort study in COPD patients in Italy
}

This article was published in the following Dove Press journal:

International Journal of COPD

27 January 2017

Number of times this article has been viewed

\section{Ugo Fedeli' \\ Alfredo De Giorgi ${ }^{2}$ \\ Nicola Gennaro' \\ Eliana Ferroni' \\ Massimo Gallerani ${ }^{3}$ \\ Dimitri P Mikhailidis ${ }^{4}$ \\ Roberto Manfredini² \\ Fabio Fabbian ${ }^{2}$}

'Epidemiological Department, Veneto Region, ${ }^{2}$ Department of Medical

Sciences, Clinica Medica Unit, School of Medicine, University of Ferrara,

${ }^{3}$ Department of Internal Medicine,

University Hospital of Ferrara,

Ferrara, Italy; ${ }^{4}$ Department of Clinical

Biochemistry (Vascular Disease

Prevention Clinic), University College

London Medical School, London, UK

Correspondence: Fabio Fabbian

Department of Medical Sciences, Clinica Medica Unit, School of Medicine,

University of Ferrara, University Hospital

of Ferrara, Via Aldo Moro 8, Ferrara

I-44I 24, Italy

Tel +390532237071

Fax +39053223 6816

Email f.fabbian@ospfe.it
Background: COPD is among the major causes of death, and it is associated with several comorbid conditions. Chronic kidney disease (CKD) is frequently diagnosed in older people living in Western societies and could impact COPD patients' mortality. We evaluated the relationship between burden of comorbidities, $\mathrm{CKD}$, and mortality in a population-based cohort of patients discharged with a diagnosis of COPD.

Methods: A longitudinal cohort study was conducted evaluating 27,272 COPD patients. Recruitment of COPD subjects and identification of CKD and other comorbidities summarized by the Charlson comorbidity index (CCI) were based on claims data coded according to the International Classification of Diseases, 9th Revision, Clinical Modification (ICD-9-CM). Severity of COPD was classified by hospital diagnosis or exemption from medical charges due to respiratory failure or previous hospitalizations for COPD. The impact of comorbidities on survival was assessed by Cox regression.

Results: Less than $40 \%$ of patients were still alive at the end of a median follow-up of 37 months (17 months for patients who died and 56 months for those alive at the end of follow-up). After adjustment for age, gender, and severity score of COPD, CKD (hazard ratio $=1.36,95 \%$ confidence interval 1.30-1.42) independently from comorbidities summarized by the CCI was a significant risk factor for mortality.

Conclusion: In spite of limitations due to the use of claims data, long-term survival of COPD patients was heavily affected by the presence of CKD and other comorbidities.

Keywords: COPD, chronic kidney disease, Charlson comorbidity index, mortality, comorbidity

\section{Introduction}

COPD is one of the major causes of death ranking fourth worldwide, and it is predicted to become the third leading cause by 2030 (http://www. who.int/healthinfo/), ${ }^{1}$ making this disease one of the major health challenges. ${ }^{2}$

The best way to reduce the prevalence of COPD is to control for risk factors; although it is generally accepted that smoking is an important determinant of the disease, other variables can contribute to its burden ${ }^{3}$ and several comorbidities contribute to the overall severity. ${ }^{4}$

COPD is associated with increased overall mortality compared with the general population. ${ }^{5}$ Frequent acute exacerbations also play an important role in decreased lung function and thereby increase disease severity and mortality. ${ }^{6,7}$

COPD is associated with several comorbid conditions such as ischemic heart disease, arrhythmia, congestive heart failure, diabetes, lung cancer, osteoporosis, and depression. ${ }^{8,9}$ 
The presence of comorbidities in COPD patients leads to increasing hospitalizations, mortality, and health care costs. ${ }^{8}$ In patients affected by mild to moderate COPD, the main causes of death are represented by cardiovascular diseases and lung cancer. ${ }^{10}$ Due to aging of the population in many developed countries, the burden of elderly COPD patients affected by several comorbidities will increase, with complex interactions among diseases leading to disability and death. ${ }^{11}$

A recent study analyzed retrospectively data from 424,418 fee-for-service Medicare COPD patients enrolled between 1999 and 2008, and the authors found that the hospitalization rates for COPD decreased: from 131 to 107 per 100 personyears for all causes, from 58 to 44 per 100 person-years for all respiratory causes, and from 73 to 63 per 100 person-years for non-respiratory causes, without any change in prevalence of COPD in the population. These data suggest that the majority of COPD subjects are managed as outpatients. ${ }^{12}$

Recently, it has been reported that acute kidney dysfunction represents an important predictive factor of in-hospital mortality (IHM) in male older adults with multi-morbidity admitted for COPD acute exacerbations. ${ }^{13}$ Moreover, adjusted mortality within the first 6 months post COPD exacerbation in patients suffering from acute kidney injury (AKI) and COPD exacerbation was 1.80-fold in comparison with those who were AKI free. ${ }^{14}$ Therefore, renal function appears to impact COPD patients' mortality. To date, limited evidence is available on the impact of chronic kidney disease (CKD) on long-term survival of COPD patients, although a recent study reported that prevalence of CKD in stable COPD outpatients was $31 \% .^{15,16}$

The aim of the study was to assess in a population-based cohort of patients discharged with a diagnosis of COPD how CKD contributes to overall mortality, taking into account the burden of other comorbidities.

\section{Methods}

\section{Study setting}

On January 1, 2010, the total population of the Veneto Region was $\sim 4,850,000$ inhabitants, and there were $\sim 800,000$ discharges from regional hospitals each year. The archive of discharge records includes all hospitalizations of residents in public and private hospitals, both in regional hospitals and outside the study area. To comply with the national law dispositions in terms of privacy, the regional health authorities removed patients' names, exact address, and other potential identifiers from the database provided for this study. One primary and up to five secondary discharge diagnoses are registered according to the International Classification of Diseases, 9th Revision, Clinical Modification (ICD-9-CM).
In Italy, hospital care is free of charge for all legal residents, who must contribute to outpatient care (laboratory tests, ambulatory care, drug costs) unless they are enrolled in lists of patients exempt from medical charges because of being affected by select chronic diseases certified by a specialist. COPD is not included among such diseases, whereas patients with respiratory failure of any origin and common comorbidities such as diabetes, renal failure, and cardiovascular disorders are exempt from costs of outpatient care specifically associated to the condition.

\section{Enrollment of the cohort}

The study was conducted in adherence to the Declaration of Helsinki. All residents in the Veneto region aged $\geq 45$ years discharged from January 1, 2008, to December 31, 2010, with a diagnosis of chronic bronchitis (ICD-9-CM code 491), emphysema (492), and other COPD (496) were identified. In the case of repeated admissions of the same patient during the above period, only the first hospitalization was considered. Subjects dying during the hospitalization were excluded.

Severity of COPD was approximated by the following criteria derived from claims data: a hospital diagnosis or an exemption from medical charges due to respiratory failure and previous hospitalizations for COPD. A three-level score was attributed to subjects with none, one, or both of the earlier criteria.

To identify comorbidities, the modified version of the Charlson comorbidity index (CCI) adapted to ICD-9-CM codes $^{14}$ was adopted based on diseases reported in the index hospitalization and in all hospital admissions in the previous 3 years. Whenever possible, single comorbidities were identified also based on exemptions from medical charges; eg, study subjects were classified as affected by CKD in the presence of discharge diagnoses identifying CKD according to the Deyo method (ICD-9-CM 582, 583, 585, 586, 588) and/or in the presence of an exemption from medical charges due to renal failure after certification by a specialist. Criteria for identifying patients with ischemic heart disease, heart failure, cerebrovascular disorders, and peripheral arterial disease were expanded according to previous studies carried out in the Veneto region. ${ }^{17}$ The CCI was computed after the exclusion of COPD and CKD, the focus of this study.

\section{Follow-up and statistical analysis}

Subjects discharged with a diagnosis of COPD were followed up by linkage with population records to assess vital status and emigration out of the region and with the regional archive of causes of deaths for the period from 2008 to 2013. Each subject was followed up from the index hospital discharge either until death or emigration outside the study area, or December 
31, 2013, whichever came first. In the Veneto region, the cause of death is coded according to the International Classification of Diseases, 10th Edition (ICD-10); it is selected from all the diseases mentioned in the death certificate by means of the Automated Classification of Medical Entities, a computer program developed by the US National Center for Health Statistics to standardize mortality statistics. ${ }^{18}$

Survival of the whole study cohort was examined by standard life-table analysis. Survival was compared between study groups using the Kaplan-Meier non-parametric method. A Cox regression model was built to investigate the impact on overall mortality of the following variables: presence of CKD, CCI categorized in three classes, severity score, age, and gender. Statistical analyses were carried out using the package Stata 13 (College Station, TX, USA). All records were collected and handled in a completely standardized anonymous manner, according to the national guidelines (Decreto Ministeriale [DM] 18/03/1998). Moreover, the study is included among the mandatory activities of the Regione Veneto Epidemiological Department, as specified by a regional law (Deleberazione della Giunta Regionale [DGR] n. 1456/2016). The DM 18/03/1998 and DGR n.1456/2016 state that the anonymized nature of data such as that used in this study means that ethical permission is not required, and that patients' written informed consent to participate in the study was not required, as the data are anonymous.

\section{Results}

Overall 27,272 patients were enrolled in the study cohort (Figure 1). Of these, 1.0\% was censored during follow-up because they emigrated out of the study area or died without the possibility of death certificate retrieval or were no longer traceable in population records. Only $39.2 \%$ of patients were still alive at the end of a median follow-up of 37 months

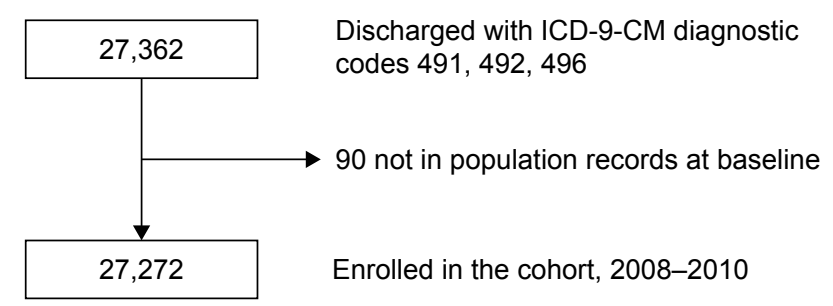

Follow-up 2008-2013

\begin{tabular}{|c|c|c|}
\hline $\begin{array}{c}10,701 \\
\text { ofive at the end } \\
\text { of the follow-up }\end{array}$ & $\begin{array}{c}16,288 \\
\text { Dead at the end } \\
\text { of the follow-up }\end{array}$ & $\begin{array}{c}283 \\
\text { Lost during } \\
\text { follow-up }\end{array}$ \\
\hline
\end{tabular}

Figure I Schematic design of the enrollment and follow-up of COPD patients. Abbreviation: ICD-9-CM, International Classification of Diseases, 9th Revision, Clinical Modification.
(17 months for patients dead and 56 months for those alive at the end of follow-up).

Table 1 shows characteristics at enrollment of study subjects. The age distribution was shifted toward old age classes: $43 \%$ of COPD patients were aged 75-84 years and $25 \% \geq 85$ years. Median age was 79 years (interquartile range $73-85$ years). About $60 \%$ of patients were males, and one of three could be classified as affected by severe/very severe COPD according to the adopted score. Most patients presented with one or more comorbidities. The most frequent diseases, tracked in at least $10 \%-20 \%$ of the study population, were heart failure, diabetes, neoplasms, cerebrovascular diseases, and CKD. The prevalence of comorbidities increased with age and leveled off in the very elderly.

The observed survival for the whole cohort was $75 \%$, $52 \%$, and $37 \%$ at 1,3 , and 5 years of follow-up, respectively. The most frequent causes of death among 16,288 decedents were circulatory disorders (mostly ischemic and other heart diseases), followed by respiratory diseases (mostly COPD, but also respiratory infections, respiratory failure, other and unspecified respiratory disorders) and cancer (Table 2). Survival was lower in patients affected by CKD (Figure 2); however, these latter patients were older than other study subjects and more frequently affected by comorbidities such as heart failure (46\%), diabetes (36\%), ischemic heart disease $(15 \%)$, and peripheral arterial disease $(12 \%)$. When determinants of survival were assessed by means of Cox regression adjusted by age, gender, and severity score of COPD, the presence of $\mathrm{CKD}$ and the presence of other comorbidities summarized by the modified CCI were significant risk factors for mortality. Results were confirmed if analyses were restricted to patients aged $<85$ years (Table 3 ).

\section{Discussion}

In our study, age, male gender, severity of COPD, CCI, and renal disease were independently related to all-cause mortality in COPD patients. Cardiovascular diseases were the most common cause of death, followed by neoplasms and respiratory causes. The risk for pneumonia, respiratory infection, myocardial infarction, and angina is high in COPD patients. ${ }^{19}$ In a previous study on $>11,000$ COPD patients, of whom $74 \%$ were 65 years or older, the risk ratio for cardiovascular mortality was 2.07 and for all-cause mortality was $2.82 .{ }^{20}$ Causes of mortality in COPD patients could vary in different reports, depending on the population studied and the study setting (eg, population-based mortality data or trials with clinical assessment of the cause of death).

Among 5,887 middle-aged volunteers with asymptomatic airway obstruction enrolled in the Lung Health Study, the main 
Table I Study subjects at baseline: demographics, severity of disease, and associated comorbidities

\begin{tabular}{|c|c|c|c|c|c|}
\hline Population features & $\begin{array}{l}45-64 \text { years } \\
(n=2,537)(\%)\end{array}$ & $\begin{array}{l}65-74 \text { years } \\
(n=5,984)(\%)\end{array}$ & $\begin{array}{l}75-84 \text { years } \\
(n=|I, 8| 7)(\%)\end{array}$ & $\begin{array}{l}\geq 85 \text { years } \\
(n=6,934)(\%)\end{array}$ & $\begin{array}{l}\text { All patients } \\
(n=27,272)(\%)\end{array}$ \\
\hline Male gender & 68.7 & 69.3 & 62.9 & 46.5 & 60.7 \\
\hline \multicolumn{6}{|l|}{ Severity score } \\
\hline 0 & 67.6 & 65.4 & 66.7 & 72.4 & 68.0 \\
\hline 1 & 29.7 & 30.6 & 29.4 & 25.2 & 28.6 \\
\hline 2 & 2.7 & 4.0 & 3.9 & 2.4 & 3.4 \\
\hline \multicolumn{6}{|l|}{ Modified Charlson index } \\
\hline 0 & 44.9 & 35.3 & 30.2 & 30.5 & 32.8 \\
\hline I & 35.2 & 36.9 & 39.1 & 40.6 & 38.6 \\
\hline 2 & 14.1 & 18.9 & 21.5 & 20.9 & 20.1 \\
\hline$\geq 3$ & 5.8 & 9.0 & 9.3 & 8.0 & 8.6 \\
\hline \multicolumn{6}{|l|}{ Selected comorbidities } \\
\hline CKD & 4.3 & 8.1 & 10.5 & 13.6 & 10.2 \\
\hline Heart failure & 11.9 & 18.9 & 26.1 & 32.6 & 24.9 \\
\hline Ischemic heart disease & 8.3 & 9.9 & 9.0 & 7.6 & 8.8 \\
\hline Cerebrovascular diseases & 4.5 & 8.1 & 11.3 & 12.3 & 10.2 \\
\hline Peripheral arterial disease & 6.0 & 8.6 & 8.5 & 5.4 & 7.5 \\
\hline Diabetes & 24.3 & 25.9 & 23.7 & 20.2 & 23.4 \\
\hline Neoplasms & 16.8 & 23.6 & 22.8 & 15.7 & 20.6 \\
\hline Dementia & 0.4 & 1.8 & 4.8 & 10.5 & 5.2 \\
\hline Liver diseases & 5.2 & 3.4 & 1.6 & 0.8 & 2.1 \\
\hline Peptic ulcer & 1.4 & 1.4 & 1.5 & 1.6 & 1.5 \\
\hline Rheumatologic diseases & 2.1 & 2.0 & 2.3 & 1.3 & 1.9 \\
\hline
\end{tabular}

Notes: Severity score was defined by none, one, or both of the following criteria: a hospital diagnosis or an exemption from medical charges due to respiratory failure; previous hospitalizations for COPD. Modified Charlson index: the modified version of the Charlson Comorbidity Index (CCl) adapted to ICD-9-CM codes was adopted based on diseases reported during hospitalizations.

Abbreviations: CKD, chronic kidney disease; ICD-9-CM, International Classification of Diseases, 9th Revision, Clinical Modification.

causes of death were lung cancer (33\%) and cardiovascular disease (22\%). ${ }^{21}$ In a pooled analysis of individual patient data from seven randomized trials enrolling $\sim 5,000$ patients with stable COPD, mortality was ascribed to respiratory causes in $34.3 \%$, cardiovascular disease in $29.8 \%$, and cancer in $20.8 \%$

Table 2 Most common causes of death among 16,288 decedents in the cohort of COPD patients

\begin{tabular}{lll}
\hline Cause of death (ICD-I0-CM) & $\mathbf{n}$ & \% \\
\hline Diseases of the respiratory system (J00-J99) & 3,720 & 22.8 \\
COPD (J40-J44, J47) & 2,652 & 16.3 \\
Asthma (J45-J46) & 28 & 0.2 \\
Other respiratory diseases (J00-J39, J50-J99) & I,040 & 6.4 \\
Circulatory diseases (I00-I99) & 6,112 & 37.5 \\
Hypertensive diseases (II0-II5) & 810 & 5.0 \\
Ischemic heart diseases (I20-I25) & 2,410 & 14.8 \\
Other heart diseases (I00-I09, I26-I5I) & 1,714 & 10.5 \\
Cerebrovascular diseases (I60-I69) & 956 & 5.9 \\
Other circulatory diseases (I70-I99) & 224 & 1.4 \\
Neoplasms (C00-D48) & 3,604 & 22.1 \\
Lung cancer (C33-C34) & 1,559 & 9.6 \\
Other neoplasms (C00-C32, C35-D48) & 2,045 & 12.6 \\
Diabetes (EI0-EI4) & 419 & 2.6 \\
Dementia, Alzheimer's disease (F0I-F03, G30) & 474 & 2.9 \\
Diseases of the digestive system (K00-K99) & 553 & 3.4 \\
Other causes of death & 1,406 & 8.6 \\
\hline Ab &
\end{tabular}

Abbreviation: ICD-I0-CM, International Classification of Diseases, I0th Revision, Clinical Modification. of cases. ${ }^{22}$ Pulmonary disease (35\%), cardiovascular disease (27\%), and cancer (21\%) were also the principal causes of death in 6,112 patients during a 3-year follow-up study ${ }^{23}$ Different populations could be aged differently, and increasing age also suggests different burden of comorbidities.

Comorbidities such as cardiovascular ${ }^{24}$ and cerebrovascular disease, ${ }^{25}$ lung cancer, ${ }^{26}$ and diabetes ${ }^{27}$ are frequently diagnosed in COPD patients and were suggested as the major

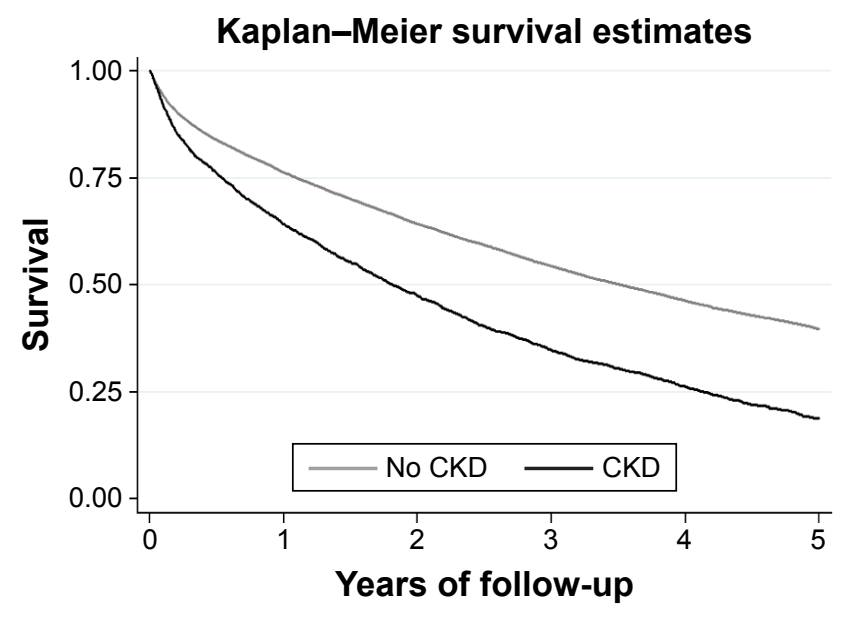

Figure 2 Survival curves for COPD patients with and without chronic kidney disease (CKD). 
Table 3 Patients discharged with a diagnosis of COPD: hazard ratios (HRs) with $95 \% \mathrm{Cl}$ for overall mortality estimated by Cox regression

\begin{tabular}{|c|c|c|c|c|}
\hline \multirow[t]{2}{*}{ Population features } & \multicolumn{2}{|l|}{ Overall cohort } & \multicolumn{2}{|c|}{ Patients aged $45-84$ years } \\
\hline & HR (CI) & $P$-value & HR (Cl) & $P$-value \\
\hline Age, years & $1.07(1.06-1.07)$ & $<0.001$ & $1.06(1.06-1.06)$ & $<0.001$ \\
\hline Females vs males & $0.76(0.73-0.78)$ & $<0.001$ & $0.74(0.71-0.77)$ & $<0.001$ \\
\hline Severity score I vs 0 & $1.39(1.34-1.44)$ & $<0.001$ & $\mathrm{I} .45(|.40-| .5 \mathrm{I})$ & $<0.001$ \\
\hline Severity score 2 vs 0 & $1.69(1.57-1.82)$ & $<0.001$ & $1.83(1.68-1.99)$ & $<0.001$ \\
\hline Charlson I vs 0 & $1.31(1.26-1.36)$ & $<0.001$ & $1.39(1.32-1.45)$ & $<0.001$ \\
\hline Charlson 2 vs 0 & $1.57(1.50-1.64)$ & $<0.001$ & $1.70(1.61-1.80)$ & $<0.001$ \\
\hline Charlson $3+$ vs 0 & $1.84(1.74-1.95)$ & $<0.001$ & $1.99(1.86-2.13)$ & $<0.001$ \\
\hline CKD & $1.36(1.30-1.42)$ & $<0.001$ & I.4I (I.33-I.50) & $<0.001$ \\
\hline
\end{tabular}

Notes: Severity score was defined by none, one, or both of the following criteria: an hospital diagnosis or an exemption from medical charges due to respiratory failure; previous hospitalizations for COPD. Modified Charlson index: the modified version of the Charlson Comorbidity Index (CCI) adapted to ICD-9-CM codes was adopted based on diseases reported during hospitalizations.

Abbreviations: HR, hazard ratio; Cl, confidence interval; CKD, chronic kidney disease; ICD-9-CM, International Classification of Diseases, 9th Revision, Clinical Modification.

causes of death in $>60 \%$ of COPD patients who died in two large randomized controlled pharmacological trials. ${ }^{10,28}$ Comorbidity also determined the need for hospitalization, length of hospital stay, and hospital readmissions for COPD.

Summarizing the burden of comorbidities by the use of a score is desirable, due to the fact that classification of patients could be immediate and it allows a better comprehension of results. Different indexes have been developed in order to determine the risk of death in COPD patients, including the BODE (body mass index [BMI], airflow obstruction, dyspnea, and exercise capacity), the ADO (age, dyspnea, and obstruction), and the DOSE (dyspnea, obstruction, smoking, and exacerbation) ones, but all of them considered a functional parameter such as the forced expiratory volume in the 1st second $\left(\mathrm{FEV}_{1}\right) \cdot{ }^{29-31}$ However, data about the prognostic value of comorbidity indices in these subjects are still a matter of debate.

The most commonly adopted index for comorbidities is the CCI, which along with metabolic and heart diseases reduced the probability to improve outcomes of pulmonary rehabilitation in inpatients and outpatients with COPD undergoing rehabilitation. ${ }^{32} \mathrm{CCI}$ has been adopted to quantify comorbidity in cohorts of patients hospitalized for acute exacerbation of COPD. ${ }^{33,34}$ Almagro et al $^{35}$ longitudinally evaluated patients hospitalized for a COPD exacerbation and found that $\mathrm{CCI}$ was associated with mortality after adjustment for age, pulmonary function, and functional status. Also in our study, CCI impacted negatively on the outcome of COPD patients. On the other hand, as well as for age, the impact of CCI on mortality depends on patients' selection. In addition to comorbidity, renal dysfunction is an important factor to be considered in the CCI calculation. In this study, we evaluated the two conditions, ie, CCI and renal function, separately and we found that renal dysfunction was a major determinant of COPD patients' survival. CKD is frequently diagnosed in older people with a prevalence of $>20 \%,{ }^{36}$ and between 2.5 and 3 million people are suspected to be affected by CKD in Italy. ${ }^{37}$ Previous studies conducted in the same country reported that renal dysfunction is independently associated with IHM due to myocardial infarction, ${ }^{38}$ stroke, ${ }^{39}$ and COPD exacerbations. ${ }^{13} \mathrm{We}$ found that renal dysfunction was a frequent comorbid condition of COPD patients, recorded in $10.2 \%$ of cases, especially if they were aged $\geq 75$ years. These data are in agreement with a recent meta-analysis suggesting that the presence of CKD was associated with increased short-term mortality during severe COPD exacerbations leading to hospitalization. ${ }^{40}$ In $>175,000$ COPD patients, all-cause in-hospital death occurred in $13.7 \%$ of cases and was associated with several comorbid conditions, including CKD. ${ }^{41} \mathrm{~A}$ recent study from the $\mathrm{US}^{42}$ evaluated 56,960 patients with CKD of whom 2,667 had COPD. The authors evaluated the impact of COPD in CKD patients by analyzing all-cause mortality and found that age, AfricanAmerican race, BMI $<18.5 \mathrm{~kg} / \mathrm{m}^{2}$, diabetes, malignancy, coronary artery disease, congestive heart failure, hypertension, and smoking status were factors associated with COPD. Survival of subjects with COPD was lower; moreover, COPD was associated with fourfold higher mortality risk of respiratory related deaths. It should be underlined that the design was different from this study, which examines the impact of renal dysfunction in a cohort of COPD patients; however, both results confirm the concurrent role of COPD and CKD in increasing the risk of death.

It has been suggested that COPD could be a manifestation of systemic inflammatory syndrome, and renal dysfunction 
in COPD patients may be associated with systemic inflammation ${ }^{43}$ and malnutrition, ${ }^{44}$ the latter two being risk factors for COPD exacerbations. ${ }^{45}$

This study has several limitations. Potentially important data such as disease severity, including the degree of renal dysfunction, were not available. COPD diagnosis was based on ICD-9-CM codes, without spirometry data, and the limited utility of these codes to define COPD has been reported. ${ }^{46,47}$ It has been shown that physicians could underestimate clinical conditions of COPD patients without considering spirometry data. ${ }^{48}$ In the same way, renal failure diagnosis was not based on glomerular filtration rate evaluation because we could not record biochemical parameters. Furthermore, analyses of claims data probably underestimated the prevalence of selected pathologies among the very elderly, such as ischemic heart diseases, peripheral arterial diseases, and liver diseases.

Variables with potential impact on mortality, such as home oxygen therapy status, respiratory disability grade, low level of continuity of care, ${ }^{49}$ and severity of illness, ${ }^{50}$ could only be approximated by claims data.

We could not take into account important determinants of health outcomes for chronic diseases, such as socioeconomic status, ${ }^{51}$ neither consider the effect of environmental factors, such as air pollution. . $2,53^{5}$

Finally, we did not take into account variables describing precisely the clinical status of patients, including BMI, smoking status, blood pressure, and therapy. Moreover, we could not ascribe renal dysfunction to any specific cause. On the other hand, our aim was merely to evaluate the impact of clinically defined comorbidity by the use of claims data on outcomes ${ }^{54}$ and specifically to evaluate the impact of a clinical comorbidity score and CKD on mortality.

\section{Conclusion}

Overall survival of COPD patients was heavily affected by the presence of comorbidities, namely, CKD. The analysis of claims data allowed investigation of long-term prognosis in a large population representative of everyday practice. These data could help health care providers in optimizing interventions and resource allocation given the increase in health care costs associated with multiple comorbidities. ${ }^{55}$ Physicians should consider CKD and other coexisting diseases when caring for COPD patients.

\section{Acknowledgment}

This study is supported, in part, by a research grant from the University of Ferrara (Fondo Ricerca Ateneo - FAR).

\section{Author contributions}

Ugo Fedeli, Alfredo De Giorgi, Nicola Gennaro, Eliana Ferroni, Massimo Gallerani, Dimitri P Mikhailidis, Roberto Manfredini and Fabio Fabbian gave substantial contributions to conception and design, acquisition of data, or analysis and interpretation of data; drafted the article or revised it critically for important intellectual content; gave final approval of the version to be published; and agreed to be accountable for all aspects of the work in ensuring that questions related to the accuracy or integrity of any part of the work were appropriately investigated and resolved.

\section{Disclosure}

Ugo Fedeli, Alfredo De Giorgi, Nicola Gennaro, Eliana Ferroni, Massimo Gallerani, Roberto Manfredini, and Fabio Fabbian had no conflicts of interest; Dimitri P. Mikhailidis has given talks, attended conferences, and participated in advisory boards and trials sponsored by Merck, Sharp \& Dohme, AstraZeneca, and Libytec. All authors participated in the data collection, analysis, and manuscript preparation. This text has been seen and approved by all authors and it is not under consideration for publication elsewhere in a similar form, in any language. The authors report no other conflicts of interest in this work.

\section{References}

1. Chronic respiratory disease: Burden of COPD [webpage on the Internet]. World Health Organization. Geneva: WHO; 2017. Available from: http://www.who.int/respiratory/copd/burden/en. Accessed January 8, 2017.

2. Decramer M, Janssens W, Miravitlles M. Chronic obstructive pulmonary disease. Lancet. 2012;379(9823):1341-1351.

3. Eisner MD, Anthonisen N, Coultas D, et al. An official American Thoracic Society public policy statement: novel risk factors and the global burden of chronic obstructive pulmonary disease. Am J Respir Crit Care Med. 2010;182(5):693-718.

4. GOLD [homepage on the Internet]. Global Initiative for Chronic Obstructive Lung Disease (GOLD): Global Strategy for the Diagnosis, Management and Prevention of Chronic Obstructive Pulmonary Disease. NHLBI/WHO Workshop Report. 2016. NIH Publication No 2701 A. Available from: http://www.goldcopd.com/. Accessed May 3, 2016.

5. LeivsethL, Brumpton BM, Nilsen TI, MaiXM, Johnsen R, Langhammer A. GOLD classifications and mortality in chronic obstructive pulmonary disease: the HUNT study, Norway. Thorax. 2013;68(10):914-921.

6. Schmidt SA, Johansen MB, Olsen M, et al. The impact of exacerbation frequency on mortality following acute exacerbations of COPD: a registry-based cohort study. BMJ Open. 2014;4(12):e006720.

7. Ferroni E, Belleudi V, Cascini S, et al. Role of tiotropium in reducing exacerbations of chronic obstructive pulmonary disease when combined with long-acting B2-agonists and inhaled corticosteroids: the outpul study. J Clin Pharmacol. 2016;56(11):1423-1432.

8. Barnes PJ, Celli BR. Systemic manifestations and comorbidities of COPD. Eur Respir J. 2009;33(5):1165-1185.

9. Sin DD, Anthonisen NR, Soriano JB, Agusti AG. Mortality in COPD: role of comorbidities. Eur Respir J. 2006;28(6):1245-1257.

10. Berry CE, Wise RA. Mortality in COPD: causes, risk factors, and prevention. COPD. 2010;7(5):375-382. 
11. Marcon A, Saugo M, Fedeli U. COPD-related mortality and comorbidities in Northeastern Italy, 2008-2012: a multiple causes of death analysis. COPD. 2016;13(1):35-41.

12. Baillargeon J, Wang Y, Kuo YF, Holmes HM, Sharma G. Temporal trends in hospitalization rates for older adults with chronic obstructive pulmonary disease. Am J Med. 2013;126(7):607-614.

13. Fabbian F, De Giorgi A, Manfredini F, et al. Impact of renal dysfunction on in-hospital mortality of patients with severe chronic obstructive pulmonary disease: a single-center Italian study. Int Urol Nephrol. 2016; 48(7):1121-1127.

14. Deyo RA, Cherkin DC, Ciol MA. Adapting a clinical comorbidity index for use with ICD-9-CM administrative databases. JClin Epidemiol. 1992; 45(6):613-619.

15. Barakat MF, McDonald HI, Collier TJ, Smeeth L, Nitsch D, Quint JK. Acute kidney injury in stable COPD and at exacerbation. Int J Chron Obstruct Pulmon Dis. 2015;10:2067-2077.

16. Yoshizawa T, Okada K, Furuichi S, et al. Prevalence of chronic kidney diseases in patients with chronic obstructive pulmonary disease: assessment based on glomerular filtration rate estimated from creatinine and cystatin C levels. Int J Chron Obstruct Pulmon Dis. 2015;10:1283-1289.

17. Ferroni E, Casotto V, Pigato M, et al. Patient and general practitioner characteristics influencing the management of non-insulin-treated diabetes mellitus: a cross-sectional study in Italy. Diabetes Res Clin Pract. 2016; 116:192-201.

18. Lu TH, Anderson RN, Kawachi I. Trends in frequency of reporting improper diabetes-related cause-of-death statements on death certificates, 1985-2005: an algorithm to identify incorrect causal sequences. Am J Epidemiol. 2010;171(10):1069-1078.

19. Soriano JB, Visick GT, Muellerova H, Payvandi N, Hansell AL. Patterns of comorbidities in newly diagnosed COPD and asthma in primary care. Chest. 2005;128(4):2099-2107.

20. Curkendall SM, DeLuise C, Jones JK, et al. Cardiovascular disease in patients with chronic obstructive pulmonary disease, Saskatchewan Canada cardiovascular disease in COPD patients. Ann Epidemiol. 2006; 16(1):63-70.

21. Anthonisen NR, Skeans MA, Wise RA, et al; Lung Health Study Research Group. The effects of a smoking cessation intervention on 14.5-year mortality: a randomized clinical trial. Ann Intern Med. 2005;142(4):233-239.

22. Sin DD, Wu L, Anderson JA, et al. Inhaled corticosteroids and mortality in chronic obstructive pulmonary disease. Thorax. 2005;60:992-997.

23. Calverley PM, Anderson JA, Celli B, et al. Salmeterol and fluticasone propionate and survival in chronic obstructive pulmonary disease. N Engl J Med. 2007;356(8):775-789.

24. Anthonisen NR, Connett JE, Enright PL, Manfreda J; Lung Health Study Research Group. Hospitalizations and mortality in the lung health study. Am J Respir Crit Care Med. 2002;166(3):333-339.

25. Hansell AL, Walk JA, Soriano JB. What do chronic obstructive pulmonary disease patients die from? A multiple cause coding analysis. Eur Respir J. 2003;22(5):809-814.

26. Mannino DM, Aguayo SM, Petty TL, Redd SC. Low lung function and incident lung cancer in the United States: data from the first National Health and Nutrition Examination Survey follow-up. Arch Intern Med. 2003;163(12):1475-1480.

27. Mannino DM, Thorn D, Swensen A, Holguin F. Prevalence and outcomes of diabetes, hypertension and cardiovascular disease in COPD. Eur Respir J. 2008;32(4):962-969.

28. McGarvey LP, John M, Anderson JA, Zvarich M, Wise RA; TORCH Clinical Endpoint Committee. Ascertainment of cause-specific mortality in COPD: operations of the torch clinical endpoint committee. Thorax. 2007;62(5):411-415.

29. Celli BR, Cote CG, Marin JM, et al. The body-mass index, airflow obstruction, dyspnea, and exercise capacity index in chronic obstructive pulmonary disease. $N$ Engl J Med. 2004;350(10):1005-1012.

30. Puhan MA, Garcia-Aymerich J, Frey M, et al. Expansion of the prognostic assessment of patients with chronic obstructive pulmonary disease: the updated BODE index and the ADO index. Lancet. 2009;374(9691):704-711.
31. Jones RC, Donaldson GC, Chavannes NH, et al. Derivation and validation of a composite index of severity in chronic obstructive pulmonary disease: the DOSE Index. Am J Respir Crit Care Med. 2009;180(12):1189-1195.

32. Crisafulli E, Costi S, Luppi F, et al. Role of comorbidities in a cohort of patients with COPD undergoing pulmonary rehabilitation. Thorax. 2008;63(6):487-492.

33. Antonelli Incalzi R, Fuso L, De Rosa M, et al. Co-morbidity contributes to predict mortality of patients with chronic obstructive pulmonary disease. Eur Respir J. 1997;10(12):2794-2800.

34. Terzano C, Conti V, Di Stefano F, et al. Comorbidity, hospitalization, and mortality in COPD: results from a longitudinal study. Lung. 2010; 188(4):321-329.

35. Almagro P, Cabrera FJ, Diez J, et al. Comorbidities and short-term prognosis in patients hospitalized for acute exacerbation of COPD: the EPOC en Servicios de medicina interna (ESMI) study. Chest. 2012; 142(5):1126-1133.

36. Zhang Q-L, Rothenbacher D. Prevalence of chronic kidney disease in population-based studies: systematic review. BMC Public Health. 2008;8:117.

37. De Nicola L, Donfrancesco C, Minutolo R, et al. Epidemiology of chronic kidney disease in Italy: current state and contribution of the CARHES study. G Ital Nefrol. 2011;28(4):401-407.

38. Fabbian F, Pala M, De Giorgi A, et al. In-hospital mortality in patients with renal dysfunction admitted for myocardial infarction: the EmiliaRomagna region of Italy database of hospital admissions. Int Urol Nephrol. 2013;45(3):769-775.

39. Fabbian F, Gallerani M, Pala M, et al. Association between in-hospital mortality and renal dysfunction in 186219 patients hospitalized for acute stroke in the Emilia-Romagna region of Italy. Angiology. 2014; 65(10):906-910.

40. Singanayagam A, Schembri S, Chalmers JD. Predictors of mortality in hospitalized adults with acute exacerbation of chronic obstructive pulmonary disease. Ann Am Thorac Soc. 2013;10(2):81-89.

41. Hasegawa W, Yamauchi Y, Yasunaga H, et al. Factors affecting mortality following emergency admission for chronic obstructive pulmonary disease. BMC Pulm Med. 2014;14:151.

42. Navaneethan SD, Schold JD, Huang H, et al. Mortality outcomes of patients with chronic kidney disease and chronic obstructive pulmonary disease. Am J Nephrol. 2016;43(1):39-46.

43. Carrero JJ, Stenvinkel P. Inflammation in end-stage renal disease - what have we learned in 10 years? Semin Dial. 2010;23(5):498-509.

44. Carrero JJ, Aguilera A, Stenvinkel P, Gil F, Selgas R, Lindholm B. Appetite disorders in uremia. J Ren Nutr. 2008;18(1):107-113.

45. McDonald HI, Thomas SL, Nitsch D. Chronic kidney disease as a risk factor for acute community-acquired infections in high-income countries: a systematic review. BMJ Open. 2014;4(4):e004100.

46. Quint JK, Müllerova H, DiSantostefano RL, et al. Validation of chronic obstructive pulmonary disease recording in the Clinical Practice Research Datalink (CPRD-GOLD). BMJ Open. 2014;4(7):e005540.

47. Molnar MZ, Mucsi I, Novak M, et al. Association of incident obstructive sleep apnoea with outcomes in a large cohort of US veterans. Thorax. 2015;70(9):888-895.

48. Mapel DW, Dalal AA, Johnson P, Becker L, Hunter AG. A clinical study of COPD severity assessment by primary care physicians and their patients compared with spirometry. Am J Med. 2015;128(6): 629-637.

49. Cho KH, Kim YS, Nam CM, et al. The association between continuity of care and all-cause mortality in patients with newly diagnosed obstructive pulmonary disease: a Population-Based Retrospective Cohort Study, 2005-2012. PLoS One. 2015;10(11):e0141465.

50. Rosenthal GE. Weak association between hospital mortality rates for individual diagnoses: implications for profiling hospital quality. Am J Public Health. 1997;87:429-433.

51. Gershon AS, Hwee J, Victor JC, Wilton AS, To T. Trends in socioeconomic status-related differences in mortality among people with chronic obstructive pulmonary disease. Ann Am Thorac Soc. 2014;11(8):1195-1202. 
52. Hu G, Zhong N, Ran P. Air pollution and COPD in China. J Thorac Dis. 2015;7(1):59-66.

53. Tian L, Ho KF, Wang T, et al. Ambient carbon monoxide and the risk of hospitalization due to chronic obstructive pulmonary disease. Am J Epidemiol. 2014;180(12):1159-1167.
54. Wallace E, Stuart E, Vaughan N, Bennett K, Fahey T, Smith SM. Risk prediction models to predict emergency hospital admission in communitydwelling adults: a systematic review. Med Care. 2014;52(8):751-765.

55. Mannino DM, Higuchi K, Yu TC, et al. Economic burden of COPD in the presence of comorbidities. Chest. 2015;148(1):138-150.

\section{Publish your work in this journal}

The International Journal of COPD is an international, peer-reviewed journal of therapeutics and pharmacology focusing on concise rapid reporting of clinical studies and reviews in COPD. Special focus is given to the pathophysiological processes underlying the disease, intervention programs, patient focused education, and self management protocols.

\section{Dovepress}

This journal is indexed on PubMed Central, MedLine and CAS. The manuscript management system is completely online and includes a very quick and fair peer-review system, which is all easy to use. Visit http://www.dovepress.com/testimonials.php to read real quotes from published authors.

\footnotetext{
Submit your manuscript here: http://www.dovepress.com/international-journal-of-chronic-obstructive-pulmonary-disease-journal
} 